\title{
FORMULASI CAIRAN PEMBERSIH AIR CONDITIONER (AC) BERBASIS METIL ESTER SULFONAT (MES)
}

\section{AIR CONDITIONER CLEANER FORMULATION BASED ON METHYL ESTER SULFONATE (MES)}

\author{
Devy Setyana, Moh Yani, dan Erliza Hambali \\ ${ }^{1)}$ Departemen Teknologi Industri Pertanian, Fakultas Teknologi Pertanian, Institut Pertanian Bogor \\ Kampus IPB Dramaga, Bogor 16680, Indonesia \\ Email: devy.setyana@gmail.com
}

Makalah: Diterima 18 Februari 2021; Diperbaiki 15 Juni 2021; Disetujui 30 Juni 2021

\begin{abstract}
Cleaning is one of the air conditioner $(A C)$ treatments that should be done within a certain period to maintain its function. The AC cleaning process cannot separate from the use of cleaning fluid as one of the main ingredients. This study aimed to obtain the most efficient formulation of AC cleaner fluid from Methyl Ester Sulfonate (MES) with Hydrogen Fluoride $(H F)$ in improving performance and seeing the effect of sonication on the effectiveness of detergent in resulting the AC cleaner. The AC cleaner formulation used the two factors Completely Randomized Design method, namely MES deposition (10\%, 20\%, 30\%) and HF concentration (1\%, $2 \%, 3 \%)$. The combination stage was based on parameters of density, viscosity, surface testing, wetting, and $\mathrm{pH}$. From these testers, the three best treatments were M1OH3 (MES 10\% + HF 3\%), M2OH3 (MES 20\% + HF 3\%), M3OH3 (MES 30\% + HF 3\%). Three samples were tested for detergency so that the best treatment was M3OH3 (MES 30\% + HF 3\%). Sonication treatment was able to improve the properties of the resulting AC cleaner, with the density value of $1.0193 \mathrm{~g} / \mathrm{cm}^{3}$ to $1,0001 \mathrm{~g} / \mathrm{cm}^{3}$, surface tension from 23.676 dyne/cm to 20.765 dyne/cm, contact angle from $32.37^{\circ}$ to $20.5^{\circ}$, pH from 2.44 to 2.9, and particle size from $10.85 \mu \mathrm{m}$ to $158.27 \mathrm{~nm}$. The post-state sample had a higher detergency power than before sonication that can increase cleaning ability by as much as 70\%. However, the resulting formulation did not have a higher detergency level than commercial AC cleaner brand $X$.
\end{abstract}

Keywords: AC Cleaner, air conditioner, $H F, M E S$, sonication

ABSTRAK

Salah satu perawatan Air Conditioner (AC) yang harus dilakukan adalah membersihkan setiap periode tertentu agar fungsinya tetap terjaga. Proses pembersihan AC tidak lepas dari penggunaan cairan pembersih sebagai salah satu bahan utama. Penelitian ini bertujuan untuk mendapatkan formulasi cairan pembersih AC dari Metil Ester Sulfonat (MES) dengan Hidrogen Fluorida (HF) yang paling efisien dalam meningkatkan kinerja pembersihan dan mengetahui pengaruh sonikasi terhadap efektifitas daya deterjensi pada cairan pembersih AC yang dihasilkan. Formulasi cairan pembersih AC ini menggunakan metode Rancangan Acak Lengkap (RAL) 2 faktor yaitu konsentrasi MES $(10 \%, 20 \%, 30 \%)$ dan konsentrasi HF (1\%, 2\%, 3\%). Tahap pengujian kombinasi terbaik didasarkan pada parameter nilai densitas, viskositas, tegangan permukaan, sudut kontak dan $\mathrm{pH}$. Dari pengujian tersebut didapatkan tiga perlakuan terbaik yaitu M10H3 (MES 10\% + HF 3\%), M20H3 (MES 20\% + HF 3\%), M30H3 (MES 30\% + HF 3\%). Tiga sampel terbaik diuji tingkat pembersihannya sehingga didapatkan satu perlakuan terbaik yaitu M30H3 (MES 30\% + HF 3\%). Perlakuan sonikasi mampu meningkatkan sifat cairan pembersih AC yang dihasilkan yaitu dari nilai densitas $1,0193 \mathrm{gr} / \mathrm{cm}^{3}$ menjadi $1,0001 \mathrm{gr} / \mathrm{cm}^{3}$, tegangan permukaan dari 23,676 dyne/cm menjadi 20,765 dyne/cm, sudut kontak dari $32,37^{\circ}$ menjadi $20,5^{\circ}$, pH dari 2,44 menjadi 2,9 dan ukuran partikel dari 10,85 $\mu \mathrm{m}$ menjadi $158,27 \mathrm{~nm}$. Sampel sesudah sonikasi mempunyai daya deterjensi lebih tinggi dibandingkan sebelum sonikasi yaitu mampu meningkatkan kemampuan membersihkan sebanyak $70 \%$. Namun formulasi yang dihasilkan belum memiliki tingkat deterjensi yang lebih tinggi dari AC cleaner komersial merk X.

Kata kunci: AC, HF, MES, pembersih AC, sonikasi

\section{PENDAHULUAN}

Saat ini kebutuhan Air Conditioner (AC) menjadi sebuah kebutuhan pokok baik bagi bangunan dengan skala penggunaan yang tinggi seperti industri, perkantoran, hotel, rumah sakit, pusat perbelanjaan, apartemen maupun bangunan dengan skala kecil seperti rumah tinggal. Menurut data Kementrian Ketenagakerjaan (2012) penjualan AC di Indonesia terus meningkat bahkan mencapai 1,48 triliyun pada tahun 2012. Keandalan fungsi pendingin ruangan harus diperhatikan dengan cara pemeliharaan atau 
perawatan komponen AC setiap 3-4 bulan untuk menjaga fungsi, umur serta kesehatan penggunanya (Suminto et al., 2014). Hal ini sering dilupakan oleh para pengguna untuk merawat komponen AC yang digunakan.

Salah satu perawatan yang dilakukan adalah dengan melalui proses pembersihan. Pembersihan AC dapat dilakukan sendiri secara konvensional atau menggunakan jasa service AC yang saat ini banyak tersedia. Proses pembersihan tersebut tentunya tidak lepas dari penggunaan cairan agen pembersih $\mathrm{AC}$ sebagai salah satu bahan utama. Cairan pembersih AC merupakan peralatan atau senyawa kimia yang biasa digunakan ketika membersihkan sekat aluminium pada sistem pendingin. Bahan pembersih AC digunakan untuk membersihkan ventilasi udara atau kisi-kisi evaporator, sehingga dapat menghilangkan debu, kuman, jamur dan bakteri pada unit AC (Polarin, 2020). Dengan demikian AC menjadi lebih dingin dan bersih.

Komponen utama pada cairan pembersih AC komersial yang populer diantaranya trichloroethylene (TCE) yang sifatnya cukup berbahaya bagi lingkungan dan kesehatan (Bowman, 2014). TCE adalah salah satu contoh dari Non Aqueous Phase Liquid (NAPL) yang sudah banyak mencemari lingkungan serta bersifat persisten dan bertoksik tinggi (Muchlis dan Mukhlisin, 2016). Selain bahan kimia biasanya komponen bahan pembersih AC juga ditambah surfaktan guna meningkatkan kemampuan daya bersihnya (Utama, 2020). Beberapa jenis surfaktan yang biasa digunakan sebagai bahan pembersih adalah Sodium Lauryl Sulfate (SLS), Linier Alkil Surfonat (LAS), dan Alkil Benzena Sulfonat (ABS). Kandungan bahan aktif berbahaya dari surfaktan tersebut bersifat karsinogenik dan dapat menimbulkan dampak negatif bagi makhluk hidup dan lingkungan karena sulit diuraikan oleh mikroorganisme sehingga dapat mencemari lingkungan serta menimbulkan iritasi pada penggunanya (Radiansyah, 2011). Selain itu pada pembersih AC komersial juga menggunakan petrolium minyak bumi yang bahan bakunya tidak terbarukan dan cukup mahal.

Melihat dampak bahaya yang terkait dengan penggunaan bahan aktif kepada manusia dan lingkungan serta bahan baku yang semakin menipis dan mahal, maka diperlukan suatu inovasi cairan pembersih AC yang berbahan baku aman, tidak berbahaya bagi lingkungan dan dengan harga relatif murah. Bahan yang dapat digunakan sebagai produk pembersih adalah bahan yang mengandung polimer alami dan berbagai surfaktan ramah dari bahan nabati. Beberapa industri surfaktan mulai menghasilkan surfaktan yang memiliki sifat bebas dari toksik, biodegradable, dan mudah diformulasikan dengan komponen lain dari berbagai macam bahan seperti kelapa sawit yang bahan bakunya melimpah di Indonesia dan terbarukan. Salah satu surfaktan alami berbasis kelapa sawit yang dapat digunakan adalah Metyl Ester Sulfonat (MES).

MES merupakan surfaktan anionik sebagai bahan aktif pada deterjen telah banyak dikembangkan karena memperlihatkan dispersi yang baik, sifat penyabunan yang baik terutama pada air dengan tingkat kesadahan yang tinggi, dan bersifat mudah terdegradasi. Bahkan MES $\mathrm{C}_{16}-\mathrm{C}_{18}$ memperlihatkan aktivitas permukaan yang baik, yaitu sekitar 90\% dibandingkan linier alkil benzen sulfonat (LABS) (Amri et al., 2009). MES akan berkerja dengan menurunkan tegangan permukaan cairan sehingga noda minyak atau debu lebih mudah terangkat. Guna meningkatkan kinerja MES dalam membersihkan noda partikulat pada sekat alumunium evaporator AC, maka tetap dibutuhkan zat kimia yang efektif. Salah satu alternatif bahan utama pengganti TEC dan zat kimia lainnya yang saat ini banyak digunakan adalah Hydrofluoric Acid (HF) yang berfungsi sebagai larutan pembersih partikulat yang sangat efektif dan relatif murah.

HF biasanya digunakan sebagai bahan untuk proses chemical cleaning logam pada peralatan fasilitas industri seperti pipa stainless steel. HF banyak digunakan dalam pembersihan stainless steel serta kategori lain termasuk aplikasi seperti pemurnian kuarsa, herbisida, menghilangkan pengotor oksida dari logam dan pemurnian logam. Bahan tersebut dapat membersihkan materi partikulat maupun debu atau kotoran yang menempel, tentunya dengan konsentrasi yang aman digunakan. Penggunaan konsentrasi HF yang aman digunakan yaitu antara 1\% - 3\% (Genuino et al., 2012). Kombinasi MES dan HF dengan konsentrasi aman diduga mampu menjadi alternatif cairan pembersih AC yang efektif. Guna meningkatkat efektivitas formulasi cairan perbesih AC ini, maka dibutuhkan sebuah sentuhan teknologi untuk meningkatkan efektivitas daya bersih dan kinerjanya.

Salah satu teknologi yang dapat diterapkan adalah teknologi ultrasonikasi. Ultrasonik merupakan sebuah sensor yang memancarkan gelombang frekuensi tertentu yaitu $20 \mathrm{kHz}$ hingga $20 \mathrm{MHz}$ sehingga mampu menimbulkan efek kavitasi akustik yang membuat partikel berukuran nanometer (Kurniawan et al., 2012). Penerapan nanoteknologi dengan sonikasi pada cairan pembersih AC ini dapat mengubah partikel AC cleaner berukuran nanometer sehingga mampu meningkatkan daya pembersihnya dan memiliki sifat fisik yang sama atau bahkan lebih baik dari formula pembersih AC komersial. Kombinasi MES dan HF diharapkan mampu menjadi alternatif cairan pembersih AC yang efektif dan ramah lingkungan sehingga dapat menjadi alternatif cairan pembersih AC. Tujuan dari penelitian ini adalah untuk menentukan formulasi cairan pembersih Air Conditioner (AC) berbasis Metil Ester Sulfonat (MES) dan Hidrogen Fluorida (HF) dengan sifat fisiko kimia terbaik. Menilai efektivitas formulasi 
dengan sonikasi terhadap kemampuan daya bersih cairan pembersih AC yang dihasilkan.

\section{BAHAN DAN METODE}

\section{Bahan dan Alat}

Bahan yang digunakan dalam penelitian ini adalah Metyl Ester Sulfonat (MES), Hidrogen Fluorida (HF), Aquades, AC cleaner komersial, pewarna dan pewangi. Alat yang digunakan dalam penelitian ini adalah erlemeyer, tabung reaksi, pipet, timbangan, hot plate stirer dan alat ultrasonikasi (Branson 1510). Alat analisis tegangan permukaan (spinning drop tensiometer), alat pengukur densitas (densitymeter anton paar DMA $4500 \mathrm{M}$ ), alat pengukur viskositas (rheometer brookfield DV-III ultra), alat pengukur sudut kontak sudut kontak (Contact Angle Analyzer Phoenix 300), turbidity meter dan $\mathrm{pH}$ meter schott.

\section{Tahapan Penelitian}

\section{Tahap Persiapan}

Tahap persiapan pembuatan formulasi AC Cleaner adalah sebagai berikut :

a. Pembuatan larutan MES dengan konsentrasi $10 \%$ (kode M10), 20\% (kode M20) dan 30\% (kode M30).

b. Pembuatan larutan HF dengan konsentrasi $1 \%$ (kode H1), 2\% (kode H2) dan 3\% (kode H3).

\section{Tahap Formulasi AC Cleaner}

Penelitian ini menggunakan formula surfaktan Metil Ester Sulfonat (MES) konsentrasi M10 (10\%), M20 (20\%), M30 (30\%) yang direaksikan dengan Hidrogen Fluorida (HF) H1 (1\%), H2 (2\%), dan H3 (3\%) dengan perbandingan volume 1:1 (Modifikasi Setyana, 2015). Formula diuji berdasarkan parameter yang dievaluasi yaitu nilai densitas (SOP for Densitymeter anton paar DMA 4500M), viskositas (SOP for Rheometer Brookfield DV-III ultra), tegangan permukaan (SOP for Spinning drop tensiometer), sudut kontak (SOP for Contact Angle Analyzer Phoenix 300) dan pH. Data yang diperoleh dianalisis statistika dengan menggunakan ragam dua arah (Two way Analysis of Variance = Two way ANOVA) metode RAL. Apabila terdapat beda nyata pada analisis ragam (ANOVA), maka dilakukan uji Duncan Multiple Range Test (DMRT) dengan taraf nyata $5 \%$. Hasil tiga perlakuan terbaik pada analisis anova diuji tingkat pembersihan.

\section{Tahap Pengujian Tingkat Pembersihan}

Tiga perlakuan terbaik dilakukan uji tingkat pembersihan yaitu pembersihan dari kotoran debu AC dan noda minyak. Tahapan pengujian tingkat pembersihan atau deterjensi sebagai berikut (modifikasi Fauziah, 2010):

a. Percobaan menggunakan plat aluminium persegi panjang dengan ukuran $20 \mathrm{~cm}$ x $28 \mathrm{~cm}$ yang sudah diberi masing-masing noda minyak $2 \mathrm{ml}$ serta debu dan kerak yang berasal dari AC kotor sebanyak 5 gram. Masing -masing plat aluminiun yang sudah diberi noda disemprotkan sampel cairan pembersih AC yang dihasilkan sebanyak $100 \mathrm{ml}$ kemudian dibiarkan selama 10 menit.

b. Sampel yang luruh dari hasil semprotan terhadap noda pada aluminium ditampung pada wadah kemudian diuji tingkat kekeruhannya (SOP for Turbiditymeter).

c. Didapatkan 1 perlakuan terbaik dari hasil uji deterjensi.

\section{Tahap Ultrasonikasi}

Hasil formulasi AC cleaner terbaik berdasarkan uji ANOVA, diproduksi kembali dengan teknologi sonikasi. Tahap sonikasi ini menggunakan alat ultrasonikasi merk Branson tipe 1510, adapun tahapannya sebagai berikut:

a. Sampel AC cleaner perlakuan terbaik dimasukkan ke dalam botol sampel sebanyak $30 \mathrm{ml}$.

b. Sampel dihomogenisasi dengan homogenizer dengan kecepatan 4000 rpm.

c. Sampel dimasukkan ke dalam alat ultrasonikasi dengan frekuensi $42 \mathrm{kHz}$, selama 60 menit.

d. Sampel diuji karakteristik nilai densitas (SOP for Densitymeter anton paar DMA 4500M), tegangan permukaan (SOP for Spinning drop tensiometer), sudut kontak (SOP for Contact Angle Analyzer Phoenix 300), $\mathrm{pH}$ ( $\mathrm{pH}$ meter schott) dan ukuran partikel (particle size analyzer).

\section{Tahap Pengujian Tingkat Kebersihan Setelah Sonikasi}

Pengujian ini dilakukan pada kombinasi terbaik (yang telah disonikasi) yaitu pengamatan tingkat kekeruhan air bekas semprotan. Tahap pengujian tingkat pembersihan sebagai berikut:

a. Disiapkan sampel AC cleaner hasil sonikasi MES dan HF serta cairan pembersih AC komersial merek $X$ masing - masing $100 \mathrm{~mL}$ untuk dimasukkan ke dalam botol penyemprot

b. Disiapkan 2 plat aluminium berukuran $20 \mathrm{~cm} \mathrm{x} 28$ $\mathrm{cm}$ dan minyak $2 \mathrm{~mL}$ serta debu kotoran AC 5 gram. Minyak dan debu dioleskan pada masing masing aluminium sehingga terdapat kotoran pada aluminium tersebut.

c. Aluminium yang sudah terkena noda minyak dan debu disemprotkan masing - masing sampel AC cleaner berbasis MES setelah sonikasi dan cairan pembersih AC komersial merk X sebanyak 100 ml. Dilakukan pengamatan pada masing - masing sampel berdasarkan kekeruhan air bekas penyemprotan (SOP for Turbiditymeter).

\section{Analisis Data}

Analisis data perlakuan tersebut menggunakan metoda Rancangan Acak Lengkap (RAL) faktorial 2 faktor. Faktor 1 adalah konsentrasi Metil Ester Sulfonat (MES) dan faktor 2 adalah konsentrasi Hidrogen Fluorida (HF). Perlakuan dilakukan tiga kali pengulangan. Adapun model matematikanya 
adalah:

$$
\begin{aligned}
& \mathrm{Y}_{\mathrm{ijk}}=\mu+\alpha_{\mathrm{i}}+\beta_{\mathrm{j}}+(\alpha \beta)_{\mathrm{ij}}+\varepsilon_{\mathrm{ijk}} \\
& \text { Keterangan: } \\
& \mathrm{Y}_{\mathrm{ijk}}=\text { Pengamatan perlakuan konsentrasi } \\
& \text { MES taraf ke-i, persentase HF taraf ke- } \\
& \mathrm{j} \text { dan ulangan ke } \mathrm{k} \\
& \mu \quad=\text { Rataan umum } \\
& \alpha_{i}=\text { Pengaruh perlakuan konsentrasi MES } \\
& \text { taraf ke-i (i=10\%, 20\%, 30\%) } \\
& \beta_{\mathrm{j}}=\text { Pengaruh perlakuan persentase } \mathrm{HF} \\
& \text { taraf ke-j ( } \mathrm{j}=1 \%, 2 \%, 3 \%) \\
& (\alpha \beta)_{\mathrm{ij}}=\text { Pengaruh interaksi konsentrasi dan } \\
& \text { persentase bahan taraf ke-j } \\
& \varepsilon_{\mathrm{ijk}}=\text { Pengaruh kesalahan percobaan }
\end{aligned}
$$

\section{HASIL DAN PEMBAHASAN}

\section{Densitas}

Gambar 1 menunjukkan nilai densitas pada perlakuan MES mengalami peningkatan setelah ditambahkan HF. Berdasarkan analisis ragam (ANNOVA) perlakuan pemberian HF pada MES telah memberikan pengaruh yang nyata terhadap nilai densitas sampel. Hal tersebut ditunjukkan dengan notasi huruf yang berbeda pada setiap angka hasil pengujian. Penambahan $\mathrm{HF} 3 \%$ pada setiap konsentrasi menunjukkan hasil pengaruh paling tinggi pada perubahan nilai densitas. Hal tersebut menunjukkan bahwa semakin tinggi konsentrasi $\mathrm{HF}$ maka semakin tinggi pula densitasnya. Hal ini dikarenakan meningkatnya jumlah molekul $\mathrm{HF}$ memungkinkan semakin besarnya pula densitas partikel pada sampel. Densitas cairan pembersih AC ini sangat dipengaruhi oleh densitas komponenkomponen penyusunnya. Hal tersebut juga berlaku pada pembersih cair yang merupakan larutan air dan bahan-bahan lain seperti surfaktan, pelarut dan bahan aktif penyusun lainnya.

Densitas dapat mempengaruhi kemampuan cairan pembersih AC untuk larut dalam air serta stabilitas emulsi dari pembersih cair tersebut. Selisih densitas yang semakin jauh dari komponen penyusunnya menyebabkan penurunan stabilitas emulsi dari pembersih AC yang dihasilkan (Fauziah, 2010). Perlakuan terbaik didasarkan pada nilai densitas yang mendekati densitas air yaitu $1 \mathrm{~g} / \mathrm{cm}^{3}$, yang menunjukkan tingkat kelarutannya dalam air semakin tinggi. Nilai densitas yang paling mendekati densitas air dengan selilish paling kecil adalah pada perlakuan penambahan HF $1 \%$ pada masing-masing konsentrasi MES. Sehingga perlakuan terbaik pada nilai densitas adalah MES dengan penambahan HF $1 \%$ yaitu $\mathrm{M} 10 \mathrm{H} 1, \mathrm{M} 20 \mathrm{H} 1, \mathrm{M} 30 \mathrm{H} 1$.

\section{Viskositas}

Gambar 2 memperlihatkan bahwa nilai viskositas berada berada pada rentan $23,3 \mathrm{cp}-189,8 \mathrm{cp}$. Berdasarkan analisis ragam (ANNOVA) perlakuan pemberian HF pada MES telah memberikan pengaruh yang nyata terhadap nilai viskositas sampel. Hal tersebut ditunjukkan dengan notasi huruf yang berbeda pada setiap angka hasil pengujian. Nilai viskositas mengalami peningkatan setelah masingmasing MES ditambahkan HF 3\%. Hal tersebut menunjukkan bahwa semakin tinggi konsentrasi HF maka semakin tinggi pula viskositasnya. Hal ini dikarenakan meningkatnya jumlah molekul HF memungkinkan semakin besar pula densitas partikel pada sampel sehingga akan meningkatkan viskositas produk. Jika nilai densitas tinggi maka larutan akan memiliki viskositas yang lebih besar (Fauziah, 2010). Viskositas yang diharapkan pada cairan pembersih AC yang dihasilkan adalah viskositas yang rendah agar larutan mampu mengalir pada kisi-kisi alumunium sistem pendingin AC secara cepat. Maka perlakuan terbaik pada pengujian viskositas adalah pada perlakuan penambaan $\mathrm{HF} 1 \%$ pada masingmasing konsentrasi MES yaitu M10H1, M20H1, $\mathrm{M} 30 \mathrm{H} 1$. Grafik hubungan antara penambahan MES dan HF pada nilai viskositas produk dapat dilihat pada Gambar 2.

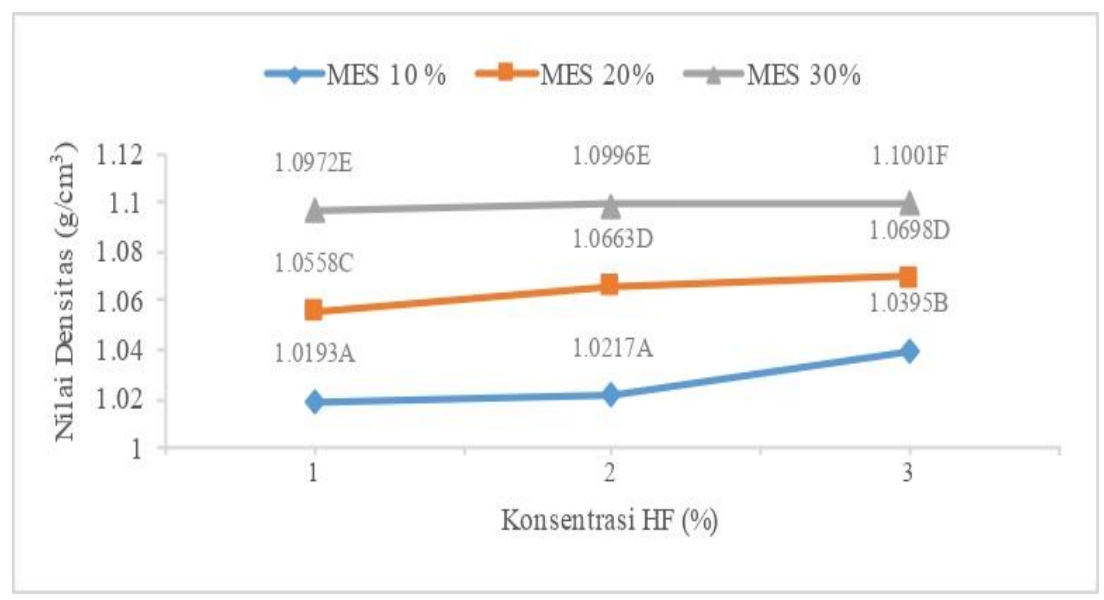

Gambar 1. Pengaruh konsentrasi HF terhadap nilai densitas pada masing-masing konsentrasi MES 


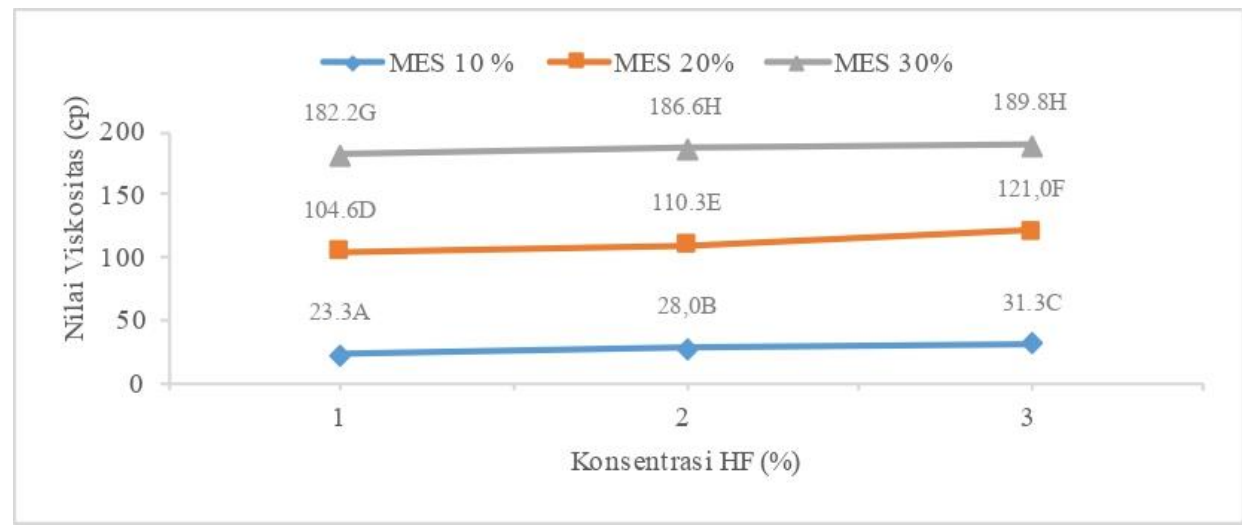

Gambar 2. Pengaruh konsentrasi HF terhadap nilai viskositas pada masing-masing konsentrasi MES

\section{Tegangan Permukaan}

Gambar 3 menunjukkan perlakuan MES dan HF pada formula mampu menurunkan tegangan permukaan pada rentan 35,373-23,676 dyn/cm. Berdasarkan analisis ragam (ANNOVA) perlakuan pemberian HF pada MES tidak memberikan pengaruh yang nyata terhadap nilai tegangan permukaan. Hal tersebut ditunjukkan dengan notasi huruf yang sama pada setiap angka hasil pengujian. Hasil penelitian menunjukkan bahwa konsentrasi HF yang tinggi menyebabkan penurunan nilai tegangan permukaan yang lebih tinggi meskipun tidak berbeda nyata. Tegangan permukaan air terbentuk pada suatu cairan dikarenakan adanya gaya tarik menarik antara molekul air dengan kekuatan yang sama. Gaya tarik menarik tersebut menyebabkan terbentuknya lapisan seperti kulit yang memisahkan antara air dan udara.

Pada formulasi ini, penurunan tegangan permukaan terjadi akibat penambahan MES, dikarenakan MES menempati ruang-ruang diantara molekul air sehingga melemahkan ikatan hidrogen yang terbentuk antara molekul air. Nilai penurunan tegangan permukaan pada perlakuan MES mengalami peningkatan setelah ditambahkan HF. Meningkatnya jumlah molekul asam memungkinkan semakin besarnya peluang terjadinya tumbukkan antara molekul asam dan surfaktan MES, dengan demikian semakin cepat reaksi penguraian yang terjadi (Probowati et al., 2012 dalam Meizar et al., 2017). Sehingga penambahan HF 3\% pada setiap konsentrasi menunjukkan penurunan tegangan permukaan yang paling tinggi yaitu $\mathrm{M} 10 \mathrm{H} 3 \mathrm{M} 20 \mathrm{H} 3$, $\mathrm{M} 30 \mathrm{H} 3$.

\section{Sudut Kontak}

Gambar 4 memperlihatkan bahwa nilai sudut kontak pada perlakuan mengalami penurunan setelah masing-masing perlakuan MES ditambah HF. Berdasarkan analisis ragam (ANNOVA) perlakuan pemberian HF pada MES tidak memberikan pengaruh yang nyata terhadap nilai sudut kontak. Hal tersebut ditunjukkan dengan notasi huruf yang sama pada setiap angka hasil pengujian. Nilai sudut kontak terkecil pada perlakuan MES dengan penambahan HF $3 \%$. Hal tersebut menunjukkan bahwa semakin besar konsentrasi surfaktan yang ditambahkan maka akan membantu dalam memperkecil sudut kontak dan memperluas area kontak larutan pembersih AC. Konsentrasi surfaktan dalam jumlah besar akan merefleksikan perilaku penyebarannya pada alumunium AC. Menurut Fayanto et al. (2018) nilai sudut kontak lebih besar dari $90^{\circ}$ tidak semua kotoran dapat dilepas dari bahan yang dibersihkan sedangkan sudut kontak lebih kecil dari $90^{\circ}$ kotoran mudah terlepas dari bahan yang dicuci. Pengujian sudut kontak pada formula bertujuan untuk menunjukkan kemampuan cepat tidaknya larutan cairan pembersih AC menyebar di permukaan aluminium AC. Nilai sudut kontak mengidentifikasikan tingkat keterbasahan (wetting). Pada penelitian ini nilai kontak terendah adalah pada perlakuan masingmasing MES dengan penambahan HF 3\% sehingga perlakuan terbaik pada M10H3 M20H3, M30H3.

\section{Nilai pH}

Gambar 5 memperlihatkan bahwa semakin besar konsentrasi HF yang ditambahkan pada masingmasing konsentrasi MES maka semakin turun nilai $\mathrm{pH}$ pada larutan. Berdasarkan analisis ragam (ANNOVA) perlakuan pemberian HF pada MES telah memberikan pengaruh yang nyata terhadap nilai $\mathrm{pH}$. Hal tersebut ditunjukkan dengan notasi huruf yang berbeda pada setiap angka hasil pengujian. Penurunan nilai $\mathrm{pH}$ dikarenakan $\mathrm{HF}$ bersifat asam dengan $\mathrm{pH}$ dibawah 3. Rata-rata rentan nilai $\mathrm{pH}$ yang dihasilakan yaitu berkisar 2,8-2,4 dimana $\mathrm{pH}$ paling asam ditunjukkan pada perlakuan MES dengan penambahan HF 3\%. Pada aplikasi cairan pembersih AC yang dihasilkan bersifat asam guna membersihkan kotoran yang sulit diambil oleh surfaktan. Jenis kotoran yang sering ditemukan dalam sistem pendingin udara bisa sangat sulit dihilangkan. Kotoran berbasis minyak akan diangkat oleh surfaktan MES. Kotoran berupa partikulat, asap, dan 
tanah lingkungan lainnya cenderung responsif terhadap larutan asam. Hal ini membuat pembersih tipe asam sangat populer untuk diaplikasikan. Larutan dengan $\mathrm{pH}$ asam akan bereaksi dengan logam, dimana reaksi ini menciptakan aksi mekanis (bubbling) secara signifikan yang berkontribusi pada efektivitas pembersihan. Reaksi ini juga menghilangkan lapisan kecil logam tempat larutan bereaksi, sehingga perlakuan terbaik pada perlakuan pada masingmasing konsenrasi MES yaitu M10H3 M20H3, $\mathrm{M} 30 \mathrm{H} 3$.
Berdasarkan pada hasil pengujian diperoleh 3 kombinasi terbaik yang dipilih berdasarkan nilai densitas, viskositas, tegangan permukaan, sudut kontak dan $\mathrm{pH}$. Dengan 3 hasil terbaik yaitu pada masing-masing konsentrasi MES dengan penambahan $\mathrm{HF} 3 \%$ yaitu M10H3, M20H3, dan $\mathrm{M} 30 \mathrm{H} 3$. Ketiga formulasi tersebut diuji tingkat pembersihan untuk menentukan 1 perlakuan terbaik.

\section{Tingkat Pembersihan (Daya Deterjensi)}

Hasil tingkat kekeruhan sampel bekas semprotan dapat dilihat pada Tabel 1 .

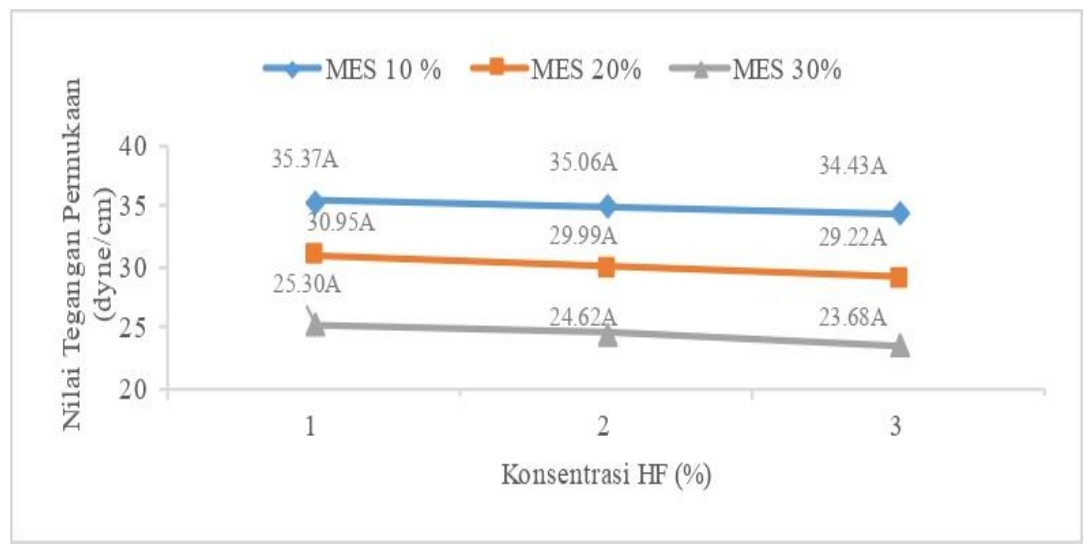

Gambar 3. Pengaruh konsentrasi HF terhadap nilai tegangan permukaan pada masing-masing konsentrasi MES

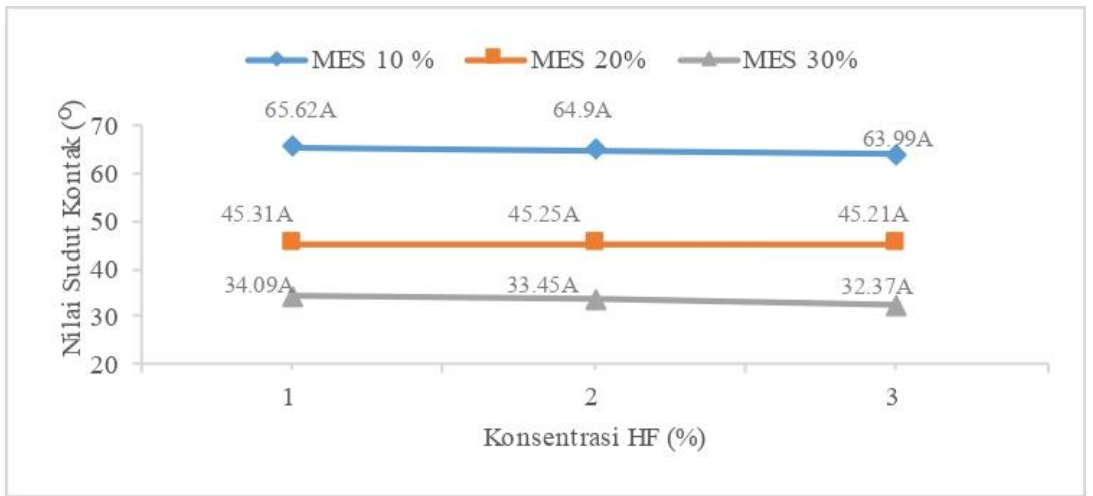

Gambar 4. Pengaruh konsentrasi HF terhadap nilai sudut kontak pada masing-masing konsentrasi MES

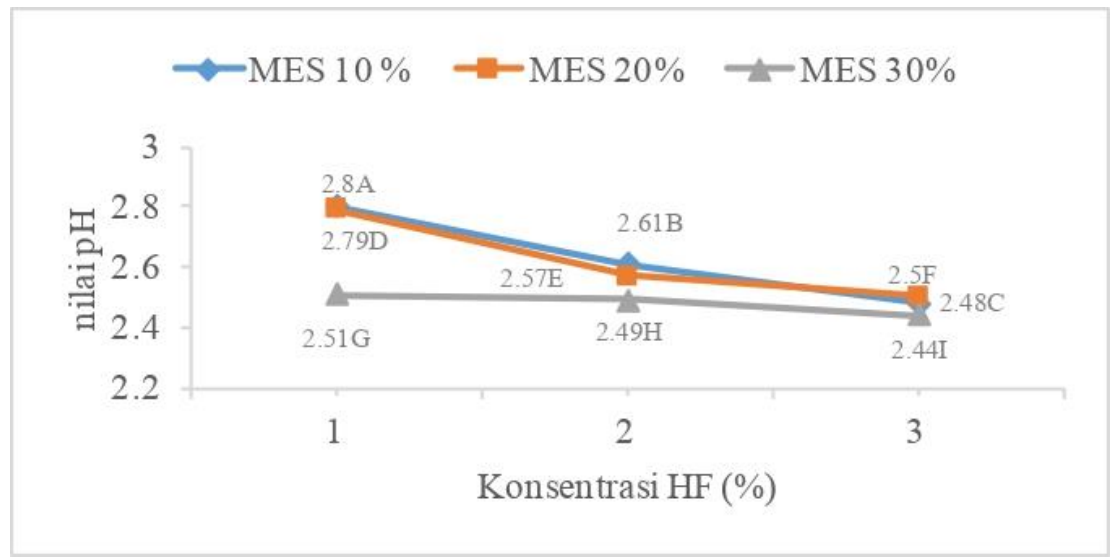


Gambar 5. Pengaruh konsentrasi HF terhadap nilai $\mathrm{pH}$ pada masing-masing konsentrasi MES

Tabel 1. Hasil pengujian tingkat kekeruhan sampel bekas semprotan

\begin{tabular}{ccc}
\hline Sampel & $\begin{array}{c}\text { Tingkat Kekeruhan Sampel } \\
\text { Sebelum Penyemprotan }\end{array}$ & $\begin{array}{c}\text { Tingkat Kekeruhan Bekas } \\
\text { Semprotan }\end{array}$ \\
\hline MES 10\%+ HF 3\% & 82 NTU & 115 NTU \\
MES 20\%+ HF 3\% & 82 NTU & 123 NTU \\
MES 30\% + HF 3\% & 85 NTU & 135 NTU \\
\hline
\end{tabular}

Tabel 1 memperlihatkan bahwa pada tingkat kekeruhan sampel bekas semprotan paling tinggi adalah pada MES 30\% dan HF 3\% (M3H3) yaitu sebesar 135 NTU dengan peningkatan kekeruhan sebesar 50\%. Semakin tinggi tingkat kekeruhan sampel maka semakin tinggi tingkat noda atau kotoran yang terbawa. Berdasarkan hasil tersebut dapat diketahui bahwa perlakuan $\mathrm{M} 3 \mathrm{H} 3$ merupakan perlakuan terbaik sebab mampu menghilangkan noda lebih tinggi. Hal tersebut dapat terjadi karena perlakuan tersebut memiliki kandungan surfaktan MES yang lebih tinggi yang mampu menurunkan tegangan permukaan lebih tiggi dengan sudut kontak yang kecil sehingga mampu mengangkat noda lebih banyak. Menurut Fayanto et al (2018), penambahan surfaktan meningkatkan kemampuan pembasah terhadap air sehingga air lebih mudah menembus kotoran yang selanjutnya mulai terjadi pemindahan kotoran.

\section{Hasil Ultrasonikasi}

Sesaat setelah dilakukan proses sonikasi sampel terlihat lebih keruh dan warna terlihat lebih memudar. Hal tersebut diduga karena terjadi proses perubahan ukuran partikel selama dilakukan sonikasi sehingga menghasilkan ukuran sangat kecil dan lebih homogen. Setelah 24 jam penyimpanan, sampel menjadi transparan. Hal tersebut dikarenakan proses pengecilan ukuran sudah selesai dan sampel sudah homogen. Perubahan ukuran partikel terjadi karena adanya pemecahan partikel dengan memanfaatkan gelombang ultrasonik. Menurut Rusdiana (2018) semakin tinggi lama waktu proses sonikasi menghasilkan nilai kekeruhan produk yang relatif kecil. Hal tersebut dikarenakan terjadinya pemecahan gelembung kavitasi pada proses ultrasonik yang melewati suatu medium menyebabkan ukuran droplet semakin kecil sehingga menyebabkan produk menjadi transparan. Ukuran yang lebih kecil dapat menghasilkan larutan pembersih AC yang mudah larut dalam air dan stabil pada saat penyimpanan pada suhu ruang. Hal tersebut terbukti dengan tidak adanya endapan ataupun adanya pemisahan fase dalam formula yang mengindikasikan formula tersebut memiliki stabilitas formula hingga $100 \%$. Hal tersebut berbeda dengan formula sebelum dilakukan proses sonikasi yaitu setelah 1 hari penyimpanan terdapat endapan dibawah larutan. Hasil sampel setelah dilakukan sonikasi dapat dilihat pada Gambar 6.
Pada penelitian ini, kestabilan emulsi setelah sonikasi dapat diukur dengan melihat karakteristik formula di dalam air seperti densitas, $\mathrm{pH}$, tegangan permukaan dan sudut kontak yang dapat dilihat pada Tabel 2.

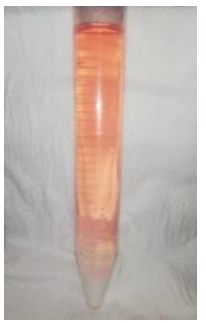

A

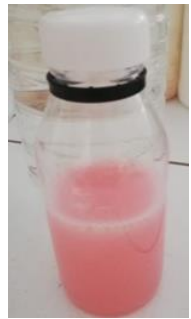

B

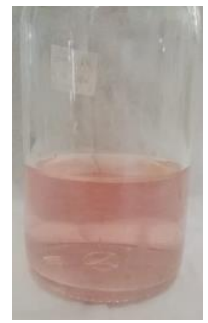

C
Gambar 6. Sampel setelah proses sonikasi A. sampel sebelum sonikasi B. sampel sesaat setelah keluar dari sonikator B. sampel setelah penyimpanan lebih dari 24 jam

Hasil penelitian menunjukkan densitas yang dihasilkan tidak jauh bebeda antara sebelum dan sesusah sonikasi, dimana sebelum sonikasi nilai densitas $1,0193 \mathrm{~g} / \mathrm{cm}^{3}$ setelah sonikasi menjadi $1,0001 \mathrm{gr} / \mathrm{cm}^{3}$. Pemecahan molekul tidak menambah bobot molekul di dalam air. Pada proses pemecahan partikel ini, hanya mempermudah partikel tersebut dalam melapisi diri dan membentuk emulsi dalam air. Densitas mempengaruhi pencampuran antara formula dengan air. Air memiliki densitas sebesar $1 \mathrm{gr} / \mathrm{cm}^{3}$. Jika densitas formula mendekati densitas air, maka formula lebih stabil mengemulsi didalam air (Murakami et al., 2014).

Tegangan permukaan juga dapat dijadikan indikator dalam melihat dispersi bahan aktif didalam air. Hasil penelitian menunjukkan terjadi peningkatan nilai penurunan tegangan permukaan dari 23,676 dyne $/ \mathrm{cm}$ menjadi 20,765 dyne $/ \mathrm{cm}$. Penurunan nilai tegangan permukaan tersebut menunjukkan adanya gaya tarik menarik permukaan yang lebih rendah pada larutan AC cleaner yang dihasilkan. Hal itu diduga pertikel menerima efek dengan adanya proses sonikasi sehingga terjadi peningkatan energi yang menyebabkan perubahan droplet lebih aktif bergerak. Partikel menyerap gelombang ultrasonik yang diberikan dari alat ultrasonikator. Peristiwa tersebut dapat meningkatkan tegangan geser yang mengakibatkan penurunan ukuran partikel (Kemala et al., 2011).

Hasil penelitian menunjukkan penurunan sudut 
kontak sebelum sonikasi sebesar $32,37^{\circ}$ menjadi $20,5^{\circ}$ setelah dilakukan sonikasi. Penurunan sudut kontak tersebut dipengaruhi oleh nilai tegangan permukaan yang rendah dan ukuran droplet yang lebih kecil. Tegangan permukaan terkait dengan kinerja surfaktan MES dalam melapisi ukuran droplet yang lebih kecil. Penyerapan suatu bahan aktif melalui medium salah satunya dipengaruhi oleh penentuan ukuran partikel. Ukuran partikel semakin kecil memudahkan bahan aktif melalui lapisan medium (Basera et al. 2015). Nilai pH pada sampel AC cleaner yang dihasilkan yaitu 2,9 dimana sebelum sonikasi pH sampel 2,44. Nilai ini menunjukkan bahwa sampel berada dalam konsentrasi asam. Perubahan nilai $\mathrm{pH}$ saat sebelum dan sesudah sonikasi menunjukkan bahwa sonikasi mempengaruhi nilai $\mathrm{pH}$ dengan semakin besarnya nilai $\mathrm{pH}$.

Berdasarkan hasil uji particle size analyzer (PSA) didapatkan ukuran partikel setelah proses sonikasi mencapai 158,27 nanometer dimana sebelum sonikasi ukurannya 10,85 mikrometer. Dari hasil uji ini dapat dikatakan bahwa sonikasi mampu mengubah partikel berskala nanometer. Hal ini sesuai dengan penyataan Yunira (2019) bahwa bahwa sonikasi telah mampu menperkecil ukuran partikel dari ukuran awal. Perlakuan sonikasi menyebabkan timbulnya kavitasi sehingga semakin lama waktu sonikasi, maka ukuran dari partikel-partikel yang terbentuk semakin mengecil (Nakahira et al., 2007). Pengecilan ukuran diharapkan mampu meningkatkan kemampuan dispersi formula di dalam air.

Setelah mengetahui karakteristik sampel yang dihasilkan selanjutnya dilakukan uji deterjensi untuk mengetahui kemampuannya dalam menghilangkan noda. Pengujian ini akan dibandingkan antara sampel sebelum dan sesudah sonikasi. Pengujian ini dibandingkan antara sampel sebelum dan sesudah sonikasi. Berikut hasil uji tingkat pembersihan sampel sebelum dan sesudah soniikasi dapat dilihat pada Gambar 7.

Gambar 7 menunjukkan bahwa sampel yang mengalami proses sonikasi mempunyai daya deterjensi lebih tinggi daripada sebelum sonikasi. Hal ini ditunjukkan pada hasil pengujian bahwa tingkat kekeruhan sampel bekas semprotan setelah sonikasi pada cairan pembersih AC lebih tinggi dari 50\% menjadi $70 \%$ dibandingkan sebelum sonikasi. Dengan demikian dari hasil tersebut dapat dikatakan bahwa sonikasi memberikan efek pada daya deterjensi yaitu dapat meningkatkan daya deterjensi sebanyak 20\%. Hal ini sesuai dengan Dormund (2005) bahwa sonikasi mampu merubah ukuran partikel berukuran nanometer yang dapat mengubah sifat dasar pada suatu molekul dengan memperbesar luas permukaan sehingga berpengaruh pada meningkatnya kemampuan dari molekul tersebut yang berguna untuk aplikasi baru.

Dalam hal ini semakin besar luas permukaan maka akan semakin mudah partikel masuk ke dalam sekat evaporator AC paling kecil sehingga mampu meningkatkan daya deterjensi cairan pembersih AC yang dihasilkan. Uji kemampuan deterjensi cairan pembersih AC yang dihasilkan juga dibandingkan dengan cairan pembersih AC komersial merek X

Tabel 2. Karakteristik sampel AC cleaner setelah sonikasi

\begin{tabular}{lcc}
\hline Karakteristik & Nilai Sebelum Sonikasi & Nilai Sesudah Sonikai \\
\hline $\begin{array}{l}\text { Densitas } \\
\text { Tegangan }\end{array}$ & $1,0193 \mathrm{gr} / \mathrm{cm}^{3}$ & $1,0001 \mathrm{gr} / \mathrm{cm}^{3}$ \\
$\begin{array}{l}\text { Permukaan } \\
\text { Sudut } \\
\text { Kontak }\end{array}$ & $23,676 \mathrm{dyne} / \mathrm{cm}$ & $20,765 \mathrm{dyne} / \mathrm{cm}^{2}$ \\
pH & $32,37^{\circ}$ & $20,5^{\circ}$ \\
$\begin{array}{l}\text { Ukuran } \\
\text { Partikel }\end{array}$ & 2,44 & 2,9 \\
\hline
\end{tabular}

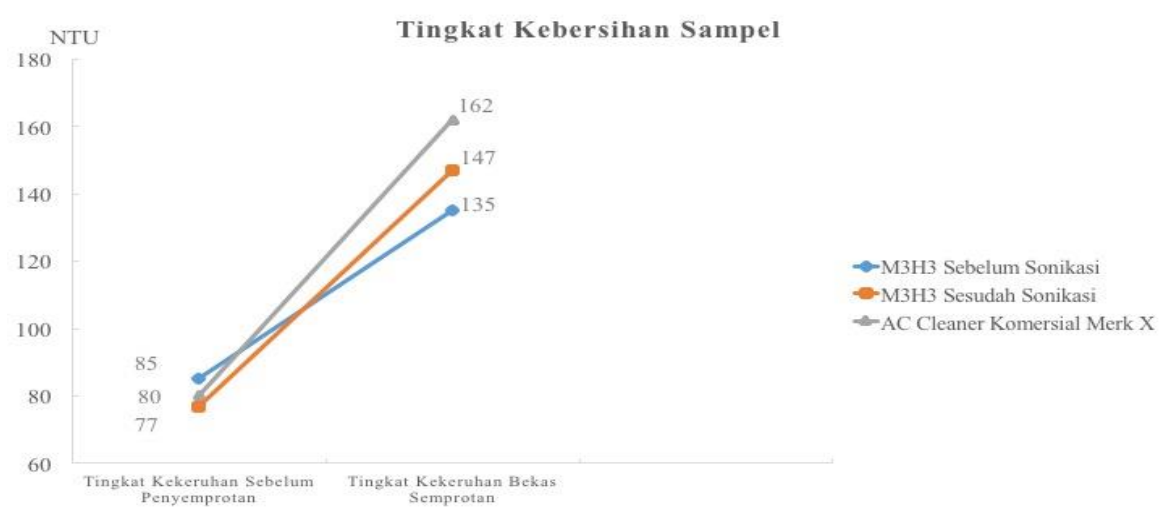


Gambar 7. Hasil pengujian tingkat pembersihan sampel sebelum dan sesudah sonikasi serta cleaner komersial

Berdasarkan hasil pengujian juga dapat dilihat bahwa nilai tingkat kekeruhan sampel pada hasil semprotan pembersih AC komersial merk X lebih tinggi daripada pembersih AC yang dihasilkan. Dimana tingkat kekeruhan sampel bekas penyemprotan pada AC cleaner hasil penelitian meningkat sebesar $70 \%$ sedangkan pada AC cleaner komersial merk X meningkat $82 \%$. Maka dari hasil pengujian tersebut dapat disimpulkan bahwa cairan pembersih AC komersial merk X lebih banyak menyerap kotoran daripada cairan pembersih $\mathrm{AC}$ yang dihasilkan. Hal ini dikarenakan surfaktan dan komponen lainnya yang digunakan pada pembersih AC komersial cukup tinggi dibandingkan cairan pembersih AC yang dihasilkan. Menurut Hidayati (2008), pada AC cleaner komersial juga banyak menggunakan berbagai jenis surfaktan dari petrolium gas, kemudian etahol, quarternary ammonium compounds dan klorida yang cukup tinggi.

\section{KESIMPULAN DAN SARAN}

Dari penelitian dapat disimpulkan bahwa formulasi cairan pembersih AC terbaik yaitu dengan kombinasi MES 30\% dan HF 1\% dengan nilai densitas $1,0001 \mathrm{gr} / \mathrm{cm}^{3}$, tegangan permukaan 20,765 dyne/cm, sudut kontak $20,5^{\circ}$, dan $\mathrm{pH}$ 2,9. Teknologi ultrasonikasi mampu memberikan pengaruh pada peningkatan daya deterjensi cairan pembersih AC yang dihasilkan sebanyak $70 \%$ dengan ukuran partikel 158,27 nm.

Saran untuk pengembangan penelitian selanjutnya untuk pengembangan cairan pembersih $\mathrm{AC}$ melalui penelitian lebih lanjut yaitu dengan variasi perlakuan sonikasi agar mengubah semua partikel sampel berskala nanometer. Selain itu penggunaan bahan lain sebagai pengganti HF pada cairan pembersih AC yang dibuat untuk meningkatkan daya deterjensi dan keamanan penggunanya.

\section{DAFTAR PUSTAKA}

Amri A, Zulfansyah, Fermi MI, Ramadani S. 2008. Pembuatan sodium lignosulfonat dengan metode sulfonasi langsung biomassa pelepah sawit. Jurnal Sains dan Teknologi. 7 (1): 6-12.

Basera K, Bhatt G, Kothiyal P, Gupta P. 2015. Nanoemulgel: a novel formulation approach for topical delivery of hydrophobic drugs. World Journal of Pharmacy and Pharmaceutical Sciences. 4 (10): 1872-1876.

Bowman J. 2014. Carefully choosing proper selection of chemicals and cleaning techniques are critical in a/c coil cleaning. RSES Journal: 2226.
Dormund IG. 2005. Synthetic Nanopartecles. Paris: Behalf of the Federal Environmental Agency.

Fauziah IN. 2010. Formulasi deterjen cair: pengaruh konsentrasi dekstrin dan metil ester sulfonat (MES) [Skripsi]. Bogor: Institut Pertanian Bogor.

Fayanto S dan Toifur M. 2018. Penentuan kualitas sabun cuci melalui tegangan permukaan berbantuan tracking dengan menggunakan software logger pro. [Thesis]. Yogyakarta: Universitas Ahmad Dahlan. doi: 10.13140/RG.2.2.36252.13446

Gaman PMKM. Sherrington. 1990. The Science Of Food 3rd Edition. Oxford England: Pergamon Press.

Genuino HC, Opembe NN, Njagi EC, McClain S, Suib S. 2012. A review of hydrofluoric acid and its use in the car wash industry. Journal of Industrial and Engineering Chemistry. 18 (2012): 1529-1539.

Hidayati S, Ilmi, dan Permadi P. 2008. Optimasi proses sulfonasi untuk memproduksi metil ester sulfonat dari minyak sawit kasar. Prosiding Seminar Nasional Sains dan Teknologi-II. Universitas Lampung, Bandar Lampung. 17-18 November 2008.

Kemala T, Sjahriza A, dan Komariah S. 2011. Emulsi dan ultrasonikasi dalam pembentukan nanoenkapsulasi ibuprofen tersalut polipaduan poli (asam laktat) dengan poli ( $\varepsilon$-kaprolakton). Jurnal Sains Materi Indonesia. 12 (3): 181187.

Kurniawan D, Nikmatin S, dan Maddu A. 2012. Sintesis nanopartikel serat rami dengan metode ultrasonikasi untuk aplikasi filler bionanokomposit. Jurnal Biofisika 8 (2): 3441.

Meizar DV, Suryani A, dan Hambali, E. 2017. Sintesis surfaktan dietanolamida (DEA) dari metil ester olein sawit menggunakan reaktor 25 liter. Jurnal Teknologi Industri Pertanian 27 (3): 328-335.

Muchlis dan Mukhlisin M. 2016. Analisis pergerakan polutan trikloroetilen dalam media berpori menggunakan sentrifug geoteknik. Jurnal Manusia dan Lingkungan. 1 (23): 12-19.

Murakami R, Motiyama H, Noguchi T, Yamamoto M, Binks BP. 2014. Effects of the density difference between water and oil on stabilization of powdered oil in water emulsions. Langmuir. 30: 496-500.

[Permen] Kementerian Ketenagakerjaan, 2012. Penetapan standar kompetensi kerja nasional indonesia kategori industri pengolahan golongan pokok industri mesin dan perlengkapan yang tidak dapat 
diklasifikasikan di tempat lain (YTDL) bidang industri air conditioner (AC). SKKNI 2016126.

Polarin. 2020. Cairan Pembersih AC. Dilihat 27 April $2020<$ https://polarin.co.id/cairan-pembersihac/>

Probowati A, Paradigma CG, dan Diyono I. 2012. Pembuatan surfaktan dari minyak kelapa murni (VCO) melalui proses amidasi dengan katalis $\mathrm{NaOH}$. Jurnal Teknik Kimia Indonesia 1(1): 424-432.

Radiansyah. 2011. Dampak kandungan deterjen dalam tanah terhadap makhluk hidup (hewan dan tumbuhan). Jurnal Riset Daerah. 7(3):243 -250 .

Raharja S dan Damayanti A. 2014. Optimasi penghambatan pengendapan jus jambu biji merah. Jurnal Agroindustri Indonesia. 3 (1): 170-180 ISSN: 2252 - 3324

Rusdiana IG. 2018. Peningkatan kinerja herbisida berbahan aktif isopropilamina glifosat dan surfaktan dietanolamida melalui proses sonikasi [Thesis]. Bogor: Institut Pertanian Bogor.

Setyana D. 2015. "Bio-nano surf" aplikasi deterjen berbasis nanoteknologi dari ekstrak getah biduri (Calotropis gigantea) sebagai alternatif deterjen ramah lingkungan [Skripsi]. Malang: Universitas Brawijaya.

Suminto C, Amilia FRS, Rochadi MT, Martano. 2014. Analisis penjadwalan kegiatan preventive maintenance ac split gedung pusat pdam tirta moedal semarang. Jurnal Wahana Teknik Sipil. 2 (19): 63-70.

Utama. 2020. AC Cleaner outdoor. Dilihat 27 April $2020<\quad$ http://www.bahankimia.com/product/ac-cleaner-outdoor/ 